\title{
Construction of Multidimensional College English Instruction Model Based on MOOC
}

\author{
Zhang Guifang \\ Department of Humanity and Management. \\ Jiangxi Police Institute \\ Jiangxi, Nanchang
}

\begin{abstract}
In the context of the rapid spread of online education represented by MOOC, the teaching of college English has to carry on great reform in instruction model, teaching method and curriculum setting so as to promote the integration of modern network technique into teaching practice. MOOCbased multidimensional college English instruction model, which features multidimensional in curriculum setting, teaching methods and evaluation, combines advantages of the traditional classroom teaching and online self-learning. This model is designed to intensify the interests of English-learning and realize the learning of individualism, independence, and persistence.
\end{abstract}

Keywords-MOOC; Multidimensional; College English Instruction model; Construction

\section{INTRODUCTION}

The development of information technology has witnessed its great changes on all areas of our society, the way of our living, our working and our learning. In higher education, the use of advanced information technology particularly challenged the traditional instruction model of teacher-headed. The exporters and learners have paid increasingly attention to the new way of learning, such as MOOC, flipped classroom [1] The teaching of college English, one of the most important part of higher education, has to face up to several troubles: how to take advantages of the information technology during the process of college English teaching and how to solve the problems in college English teaching with the help of MOOC.

\section{FEASIBILITY OF THE INTEGRATION OF MOOC WITH THE} COLLEGE ENGLISH MULTIDIMENSIONAL INSTRUCTION MODEL

College English course, which combines implement and humanity, focuses on the transfer of knowledge about English linguistic knowledge, applied skills, cross-cultural communication and learning strategy. Therefore, college English course is a system of organic integration such categories as integrated English, language skills, language culture and professional English in the form of compulsory course and elective course. According to the requirement and quality of college English course, during the process of English learning, English learners should acquire the language skills and intercultural communication competence, with which they can communicate fluently in their life and work of future. The quality of college English course and the social requirement determine that the reform of college English course have to agree with the quality of college English course, meet the demand of social development and student individualizing development.

MOOC, the abbreviation of the Massive Open Online, is a large-scale public online course. With the widely popularization of computers or mobile terminal equipment, it makes people easier to get access to advanced educational resource from the most top universities of all around the world. Owing to MOOC, the long-overdue problems in English teaching have been properly solved, such as dissatisfaction with the sole teaching contents aroused from the English learners of different English level, shortage of quality and quantity of knowledge input, lack of English teachers and educational finances. No matter who you are or where you are, every learner can select any courses online according to his interests and English level so as to realize individualized learning. Except for the massive input, English learner can output what they have picked up instantly by means of intelligent evaluation technology of MOOC so much so that the self-efficacy of English learners can be satisfied. During the interactive knowledge of input and output, the English learners are allowed to actively participate in the evaluation of English teaching, which in return push the building and improvement of English teaching [2].

\section{CONNOTATION OF MULTIDIMENSIONAL COLLEGE ENGLISH INSTRUCTION MODEL}

With reference to the college English course requirement and advantages of MOOC, the multidimensional college English instruction model comes into being in this context to solve the above problems appearing in college English teaching by appliance of information technology to college English teaching via MOOC [3]

Multidimensional college English course model is a new English instruction concept model, which involves diverse teaching methods, diverse teaching contents, diverse evaluate system. On the foundation of virtuality and reality combination, Multidimensional college English course model, existing online as well as offline, out of class as well as in the class, aims to break through the limitations of time, space and teachers level and appears in web-assisted autonomous learning classroom, ppt-assisted classroom and web-assisted elective course classroom. Multidimensional College English instruction model lies in the following features, diversification 
of curriculum content setting, diversification of teaching method, multidimension of evaluate system and informatization of teaching platform.

\section{A. Diversification of curriculum content setting and diversification of teaching method}

With the new instruction model, the English courses have to be opened enough for the learners to choose to satisfy their expectation, such as EGP (English for general Purpose), ESP (English for Special Purpose) and humanistic quality educational course related to western countries [4]. English learners can choose the courses they like via MOOC. Meanwhile they can communicate with or get help from teachers or peers on communicating platform. Compared with the traditional instruction model, teachers are not leaders but an instructor, instructing learners to participate in English learning on their own by means of different teaching methods, such as discussing, cooperating, practice, performing, inquiring etc.

\section{B. Multidimension of evaluate system}

English learners' learning record will be evaluated by formative and summative assessment so as to encourage English learners not only are required to concern about the point of final exam but also emphasize on the process of learning. Network learning platform, network examination platform, network evaluate platform make it possible to set up the diversified evaluate system.

\section{Informatization of teaching platform}

Multidimensional college English instruction model breaks through the traditional onefold teaching environment limited in classroom. It is a multidimensional teaching and communicating platform including MOOC, web-based multimedium classroom, web-based autonomous learning classroom, language lab and other intelligent equipment, which provide English learners various access to different courses associated with English. On this platform the English learners' requirements of individuality, personal autonomy and practice can be fully achieved.

\section{CONSTRUCTION OF COLLEGE ENGLISH MULTIDIMENSIONAL INSTRUCTION MODEL BASED ON MOOC}

The success of college English multidimensional instruction model depends on the setting of curriculum course system, regulation of English teaching contents and building of teaching platform based on the advanced information technology.

\section{A. To set up the curriculum course system combined basic compulsory courses with advanced elective courses}

College English courses consists of several categories including integrated course, language skill course, language and culture course, professional English course, academic English course. All of the courses should be completed in three stages: elementary stage, development stage and professional enhancement stage.
1) Elementary stage. English learners can be divided into two groups according to their English level: Level A with strong foundation of English language and Level B with weak foundation. The two groups are equipped with different textbooks, teaching contents, teaching methods, teaching plan as well as assessment standard based on their English level so that all English learners of different levels are greatly interested in participating English learning. The courses on this stage are compulsory, which aims to carry out the teaching of EGP and promote learners' integrated language skills of listening, speaking, reading, writing, translating. After the elementary stage, English learners are supposed to pass College English Test Level 4 or Level 6, an authoritative English level test in China.

2) Development stage. The teaching contents of this stage consist of three categories: English knowledge-oriented courses, language skill- oriented courses and application- oriented courses. English knowledge-oriented courses cover courses of western culture, western literature, Western history, western politics etc. Language skill- oriented courses cover English listening course, English speaking course, English writing, English translating course. Application-oriented courses cover English academic English, English thesis writing, English public speech and debate etc. In course selection system assisted by information technology, all these courses can be elected and acquired on MOOC on their own according to their interests and English level.

3) Professional enhancement stage. ESP, which covers professional English courses such as business English, computer English, legal English etc. involved in this stage. College English should be combined with the professions to realize the function of English as tool so as to increase the value of the English curriculum to meet the needs of the individual and social development. English learners are supposed to elect the professional English course in the light of their majors or their future professions.

\section{B. To construct the multidimensional teaching platform combined the classroom and network}

The multidimensional teaching platform consists of traditional real classroom and virtual online classroom. The two classes support and supplement each other while display their respective advantages.

Traditional real classroom. Traditional real classroom is composed of the multimedia classroom and language lab, in which the teacher acts not as a leader but as an instructor, supervisor and judge, who instruct English learners what to learn, where to learn, how to learn and supervise or encourage English learners to complete their learning tasks, and the teachers are supposed to evaluate their English learning objectively by means of formative and summative assessment as well. English learners are helped to look into the language knowledge in traditional classroom through the classroom demonstration, discuss, argument or communication with teachers face to face [5]. The traditional real class is related to the virtual online classroom, in which English learners are 
required to preview what will be touched in next traditional real classroom.

Virtual online classroom. The virtual online classroom is made up of online learning system, online assessment system and online communication system which is hooked up to each other assisted by internet. Massive amount of high-quality learning resource can be achieved in learning system, which includes teaching plan, teaching video, PPT and links of MOOC etc. [6]. English learners are supposed to learn automatically according to their own elective courses, interests and majors. Apart from learning automatically, English learners can evaluate the extent to which they acquire the language knowledge immediately after learning in assessment system owing to advanced information technology. Any doubt can be solved by communicating with their teachers or learning peers online.

Traditional real classroom and Virtual online classroom don't exist separately but supplement each other (as it is shown in Figure 1. Combined the traditional real teaching with virtual online teaching, the college English multidimensional instruction model provides English learners with flexible learning accesses and large amount of learning resource and a completely new instruction model, which is dominated by teachers and centered as English learners, comes into being.

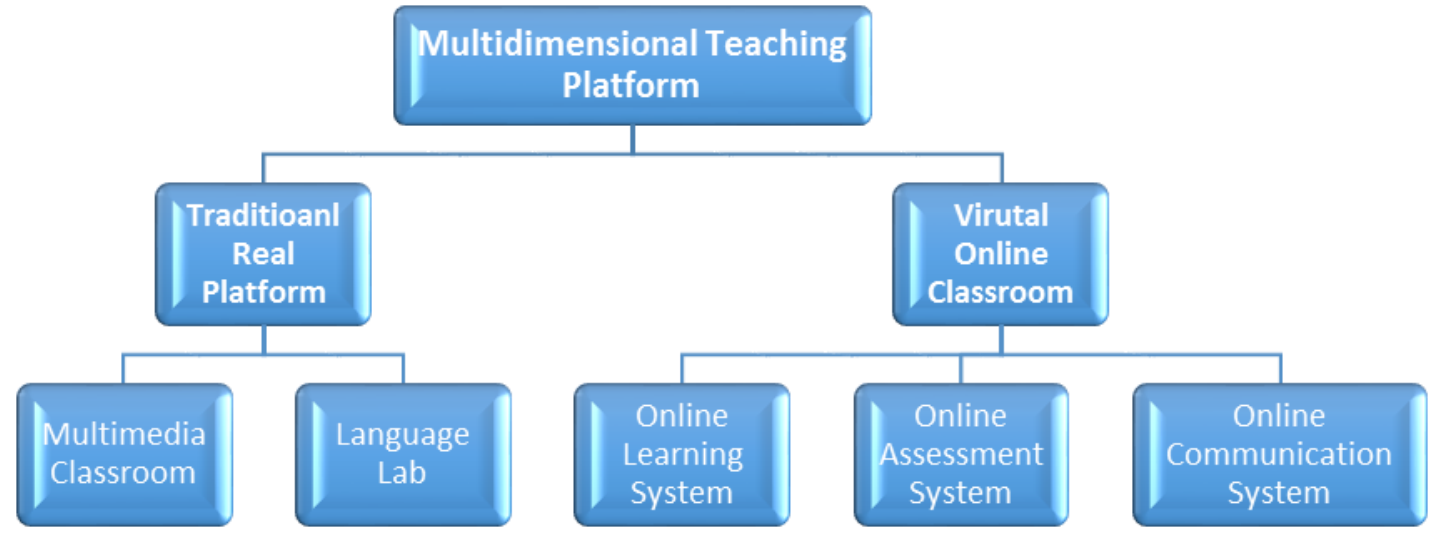

Fig. 1. Multidimensional Teaching Platform based on MOOC

\section{CONCLUSION}

With introduction of information technology and MOOC in particular into educational area, the traditional onefold instruction was challenged to get individualized and diversified. When it comes to college English, the college English multidimensional instruction model is emerged, which caters to principles of guiding ideology of Chinese education information development. This new model features the massive high-quality education resource sharing, the subject status of English learners in learning and the dominate role of teachers in teaching, which coincides with the trend of the formation of students' individualized learning and the development of students' autonomous learning ability [7].

\section{ACKNOWLEDGMENT}

First of all, I'd like to extend my sincere gratitude to Xue Huijuan, my director, who has provided me with valuable guidance in every stage of the writing of this thesis. Without her enlightening instruction, impressive kindness and patience, my thesis will be always on the way. Xue's rigorous academic attitude and extensive learning style encouraged me to keep on exploration of foreign language teaching, which is great helpful to the thesis.
Besides, I'd like to thank my colleagues, who provided me useful statistics and cases from teaching platform and supported me technological aids.

Last but not least, I want to express my heartfelt appreciation to all the scholars whose articles, books and ideas I quote directly or indirectly in my thesis.

\section{REFERENCES}

[1] Ma Xiufang. Design of MOOC in the Social Network Environment [J]. China Educational Technology, 2015,12:59-64. (In Chinese)

[2] Swain, M. Communicative competence: Some roles of comprehensible input and comprehensible output in its development [A]. In Gass, S. and Madden, C. (eds). Input in Second Language Acquisition [C]. New York: Newbury House, 1985: 235-256.

[3] Zhuang Qimin. The Current Situation and Development Trend of College English Instruction[J], Journal of University of Shanghai for Science and Technology, 2013, 9(3) : 264-268. (In Chinese)

[4] Wang Shouren. Interpretation of Key Points in Guidelines on College English Teaching, Foreign Language World, 2016 (3). (In Chinese)

[5] Wang Lu. The exploration and application flipped classroom teaching mode based on MOOC in college English teaching class[J]. Journal of higher learning research,2015(9). (In Cninese)

[6] Li Manli. The characteristic and teaching design exploration of MOOC[J]. Research On Education Tsinghua University,2013(8). (In Chinese)

[7] Ma Wulin,Hu Jiasheng. The impact and reconstruction of international MOOC on the college English curriculum in our country [J]. Computerassisted foreign language education,2014 (3). (In Chinese) 